\title{
Effect of Y-90 SIR-Spheres Therapy for Multiple Liver Metastases in a Variety of Tumors
}

\author{
Isis W. Gayed', Hisham Wahba ${ }^{2}$, David Wan', Usha Joseph ${ }^{3}$ and Ravi Murthy ${ }^{4}$
}

${ }^{1}$ The University of Texas-Houston Medical School, Department of Diagnostic and Interventional Imaging, Texas ${ }^{2}$ National Cancer Institute Cairo Egypt, Department of Diagnostic Radiology, Texas ${ }^{3}$ M.D. Anderson Cancer Center, Texas

${ }^{4}$ Department of Interventional Radiology, Texas

\begin{abstract}
Objective: To evaluate the outcomes of patients receiving Y90 SIR-Spheres in patients with multiple liver metastases from different tumors.

Methods: 29 consecutive patients with multiple liver metastases from colorectal (13), Islet cell tumors (9), carcinoid tumors (4) or non-small cell lung cancer (3) who were treated with Y-90 SIR-Spheres between March, 2003 and February, 2006 were included. Only patients who had follow-up radiological exams at our institution were included. Data regarding Y-90 SIR-Spheres dose, lobe of liver treated, and chemotherapy (CTx) administered were collected. Patients' outcomes were evaluated based on radiological evidence of change in size and number of liver metastases.
\end{abstract}

Results: The study population included 8 females and 21 males at a mean age of $60 \mathrm{y}$. The mean Y-90 SIR-Spheres dose administered was $39.8 \mathrm{mCi}$. Both lobes of the liver, the right lobe only or the left lobe only were treated in 26, 2, 1 patients, respectively. Sixteen patients received Y-90 SIR-Spheres after CTx failure, 5 patients as adjuvant therapy after completion of CTx, 7 patients as concurrent therapy and one patient refused repeat CTx. The mean interval between the last CTx and Y-90 SIR-Spheres was 108 days. Four patients (14\%) demonstrated radiological improvement and $9(31 \%)$ were stable for a mean interval of 2.8 mo. after Y-90 SIR-Spheres infusion. Sixteen patients $(55 \%)$ demonstrated continued progress of liver metastases. or stabilizing multiple liver metastases from a variety of tumors.

\section{Introduction}

The eradication of multiple liver metastases from different tumors is a difficult goal to achieve in most tumors. Different chemotherapeutic agents and regimens are being tried to evaluate best outcomes. External beam radiation therapy is limited by the maximum tolerable dose to normal liver parenchyma of 30$35 \mathrm{~Gy}$ which is insufficient to treat liver metastases. More selective internal radiation therapy to liver metastases using Y90 labeled microspheres is an acceptable alternative with multiple studies demonstrating its effects in treating metastases from colorectal cancer (Lim et al., 2005; Kennedy et al., 2006; Gray et al., 2001) and hepatocellular cancer (Lau et al., 1998; Ho et al., 1998; Sangro et al., 2006). Yettrium-90 SIR-Spheres are biocompatible microspheres with a size between 20-40 microns that contain Yettrium-90 (Y-90). Y-90 is a pure beta emitter with a half life of 64 hours and mean radiation energy of 0.93 $\mathrm{MeV}$. The average range of travel of the beta particles is $2.5 \mathrm{~mm}$ and the maximum is $11 \mathrm{~mm}$ in soft tissue. Liver metastases
Conclusion: Y-90 SIR-Spheres therapy is useful in reducing

receive a higher portion of the SIR-Spheres compared to normal liver due to higher vascularity of the tumor or around it with predominant blood supply from the hepatic artery through which SIR-Spheres are injected.

Previous studies used different means of evaluating response to the treatment with variability in therapy approach and combination with chemotherapy (Wong et al., 2006; Lau et al., 1994; Sharma et al., 2007; Mancini et al., 2006; Stubbs and Wickremesekera, 2004; Gray et al., 1992). Thus, there is a wide range of previously reported responses.

Our study aims to evaluate the response to Y-90 SIR-sphere doses in liver metastases from other primary tumors with particular interest in its effect on metastases from neuroendocrine tumors since they tend to be vascular in nature. We also evaluated the toxicity associated with this form of therapy in our patient population.

\section{Materials and Methods}

Upon approval of the study by the M.D. Anderson Cancer Center institutional review board (IRB), we performed a retrospective review of consecutive patients with multiple liver metastases from a variety of primary tumors treated with Y-90 SIR-Spheres between March 2003 and February 2006. Data was collected regarding tumor type, approximate tumor burden in the liver, Y-90 SIR-sphere doses, and prior concomitant therapies. The CT scan reports were reviewed to collect data about improvement, stability or progression of liver lesions as determined by the routine reading radiologist. Follow up of results of SIR-sphere therapy was measured based on change in size of tumor metastases on serial computed tomography (CT) scans or Magnetic resonance imaging (MRI) of the abdomen. Additionally, the CT scans were reviewed by an experienced radiologist for evaluation of response to therapy from baseline scans. A general appearance of decrease or increase in size of multiple metastases with measurements of the largest lesion in shortest diameter was performed. A change of $\geq 3 \mathrm{~mm}$ in the

*Corresponding author: Isis W. Gayed, M.D., University of Texas-Houston, Medical School, Department of Radiology, 6431 Fannin, Suite 2.130b, Houston, Texas 77030, Tel: 713-704-1789; Fax: 713-704-1596; E-mail: Isis.W.Gayed @uth.tmc.edu

Received February 22, 2010; Accepted March 29, 2010; Published March 29, 2010

Citation: Gayed IW, Wahba H, Wan D, Joseph U, Murthy R (2010) Effect of Y-90 SIR-Spheres Therapy for Multiple Liver Metastases in a Variety of Tumors. J Cancer Sci Ther 2: 043-046. doi:10.4172/1948-5956.1000021

Copyright: @ 2010 Gayed IW, et al. This is an open-access article distributed under the terms of the Creative Commons Attribution License, which permits unrestricted use, distribution, and reproduction in any medium, provided the original author and source are credited.

J Cancer Sci Ther
Volume 2(2) : 043-046 (2010) - 043 
Citation: Gayed IW, Wahba H, Wan D, Joseph U, Murthy R (2010) Effect of Y-90 SIR-Spheres Therapy for Multiple Liver Metastases in a Variety of Tumors. J Cancer Sci Ther 2: 043-046. doi:10.4172/1948-5956.1000021

largest liver metastasis was considered a significant change in size. The readings of the experienced radiologists agreed with the routine report on record for all the patients. Patients who had no adequate radiological evaluation of the outcome of therapy based on repeat CTs scans after therapy at our institution were excluded from the study.

Patients' symptoms before and after therapy with SIR-Spheres were also recorded with special attention to the known side effects of the SIR-sphere therapy as per the product insert. The side effects were classified according to the Common Terminology Criteria for Adverse Events (CTCAE) (version 3) classification (NCI, 2006). Interval to progression as seen on radiologic exams was extracted from available medical record and radiological exam reports.

\section{SIR-Spheres Therapy Planning}

All patients had a pre-therapy planning arteriography to map the anatomy of blood flow through the hepatic, celiac and superior mesenteric artery. Special attention was also directed towards apparent blood supply or arterial variants during the arteriography and the need for embolization. The hepatic arterial catheter used for the angiogram is left in place and the patient is subsequently transferred to the Nuclear Medicine Department for infusion of Tc-99m MAA through the hepatic arterial catheter with subsequent planar imaging of the chest and abdomen to evaluate the degree of shunting to the lung and/or extra hepatic organs in the abdomen. Patients with calculated lung shunting of $>20 \%$ are not qualified of treatment with the SIR-Spheres. The required dose was calculated using the empirical model

\begin{tabular}{|c|c|}
\hline $\begin{array}{c}\text { The \% tumor burden } \\
\text { in the liver }\end{array}$ & $\begin{array}{c}\text { Recommended } \\
\text { Y-90 SIR-Spheres dose } \\
\text { GBq (mCi) }\end{array}$ \\
\hline$>50 \%$ & $3.0(81)$ \\
\hline $25-50 \%$ & $2.5(68)$ \\
\hline$<25 \%$ & $2.0(54)$ \\
\hline
\end{tabular}

Table 1: The empirical method of Y-90 SIR-Spheres dose calculation.

(Table 1) recommended in the product insert. A reduction in the dose by $20 \%$ in patients with lung shunt between $10-15 \%$ and by $40 \%$ for lung shunt between $16-20 \%$ was considered in dose calculation. Patients with lung shunt greater than $20 \%$ were not treated. Details of the technique of administration of the Y-90 SIR-sphere therapeutic dose through the hepatic arterial catheter has been described by our interventional radiologists in a prior publication (Murthy et al., 2005).

\section{Results}

A total of 29 patients were included in the study with a mean age of 59.9 y (range 27-77 years). Eight patients were females and 21 were males. Thirteen patients had multiple liver metastases from colorectal cancer, 13 from neuroendocrine tumors, and three from non-small cell lung cancer. The tumor burden in the liver was less than $25 \%$ in five patients between $25-50 \%$ in 11 patients and $>50 \%$ in 13 patients. Sixteen patients received Y-90 SIR spheres after chemotherapy failure, five patients as adjuvant therapy after completion of chemotherapy, seven patients as concurrent therapy, and one patient refused repeat chemotherapy. The mean interval between the last chemotherapy and Y-90 SIR spheres therapy was 108 days.
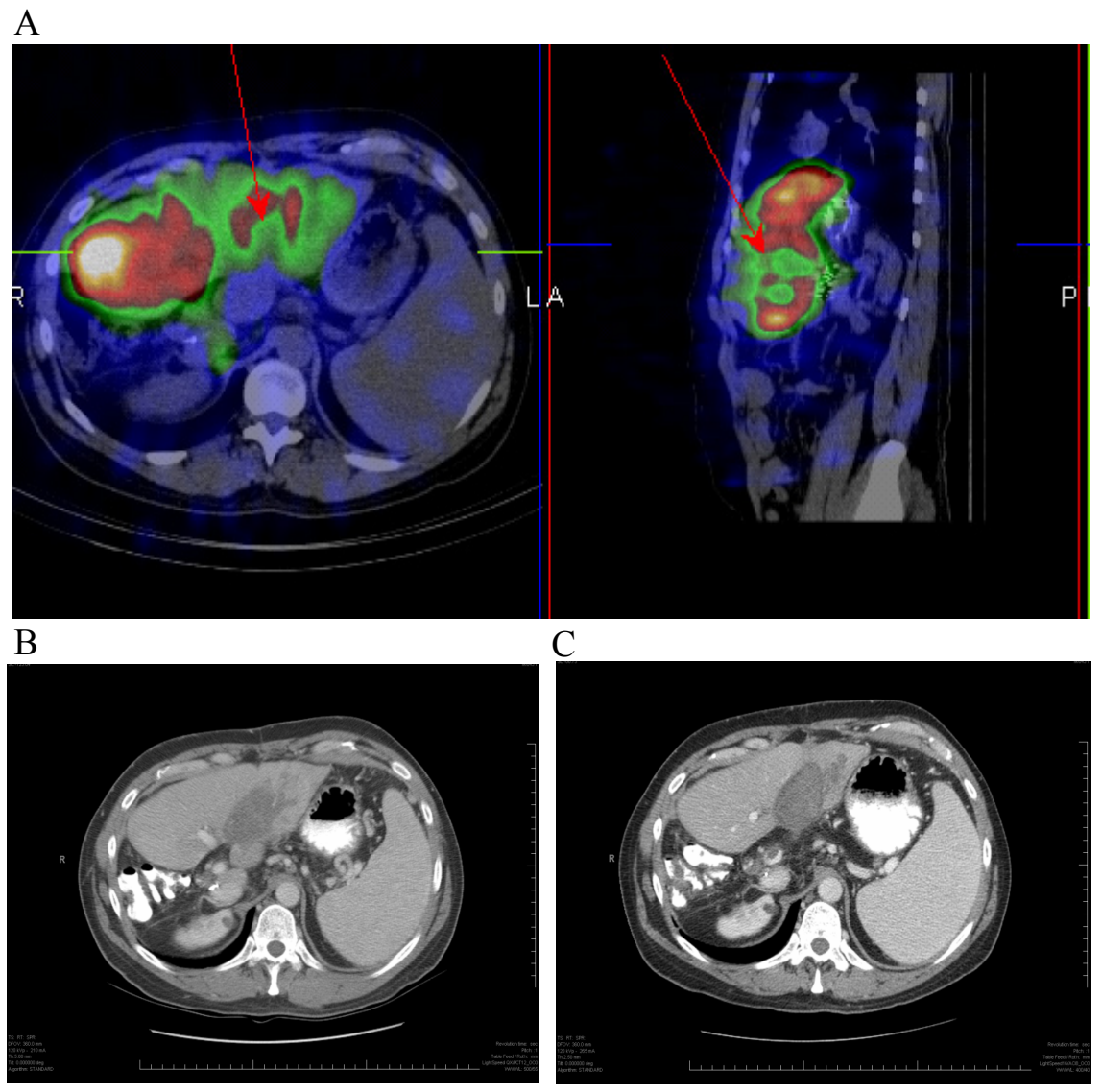

Figure 1: (A) SPECT-CT Fusion Images demonstrating the Y-90 SIR-Spheres distribution around liver metastases from islet cell cancer. (B) CT scans of the same patient prior to and (C) after therapy with Y-90 SIR-Spheres demonstrating mild decrease in size of the largest liver metastasis. 


\section{Journal of Cancer Science \& Therapy - Open Access \\ JCST/Vol.2 Issue 2}

Nineteen patients received radioembolization of both lobes of the liver at the same time, seven patients underwent radioembolization of each lobe of the liver on separate days (mean interval between each lobe therapy is 42 days), 2 patients received radioembolization to the right lobe only and another patient to the left lobe only. The mean lung shunting fraction of the Tc99m MAA as calculated from scintigraphy images was $6.6 \%$ (range 2-17\%). The mean total administered Y-90 SIR spheres dose was $39.8 \mathrm{mCi}($ median $=41 \mathrm{mCi})$.

The mean follow-up interval for all patients was 10 months after Y-90 SIR spheres therapy (median= 7.3 months). During this interval, four patients improved (14\%) (Figure 1), 8 were stable $(28 \%)$ for short interval, one patient $(3 \%)$ demonstrated mixed response to therapy and 16 patients $(55 \%)$ continued to progress. The median progression free interval for the patients that demonstrated improvement and those who were stable for some time was 4.5 months (mean $=2.8$ months). The details of patients' outcomes per tumor type are demonstrated in Table 2.

Adverse reactions from the Y-90 SIR spheres were encountered in 19 patients $(66 \%)$ within the first week after radioembolization. An additional patient demonstrated rapid progression of the disease which hindered clear delineation of adverse effects from underlying disease related symptoms. However, the adverse effects were grade 1 or 2 in 16/19 patients. Only 2 patients complained of severe abdominal pain immediately after the radioembolization and one had severe anorexia that lead to weight loss. These three patients were considered to have grade 3 side effects.

\section{Discussion}

Y-90 SIR-Spheres have been previously proven to be of benefit mainly in primary liver tumors (Lau et al., 1998; Sangro et al., 2006; Lau et al., 1994) and liver metastases from colorectal cancer (1-3). Our study demonstrates the beneficial effect of Y90 SIR spheres therapy in treating liver metastases from neuroendocrine tumors and non-small cell lung cancer in addition to colorectal cancer. The literature about the role of Y90 SIR sphere therapy in treating liver metastases from different tumors is scarce (Gulec et al., 2007; Jiao et al., 2007). Gulec et al. (2007) included 10 out of 40 patients with neuroendocrine liver metastases and 4 patients with liver metastases from breast cancer in his study population (Gulec et al., 2007). Jiao et al. (2007) study population consistent mainly of patients with metastases from colorectal cancer (10/21 patients) and the remainder of the patients were from a variety of different tumor

\begin{tabular}{|l|l|l|l|l|l|}
\hline Tumor Type & Progression & $\begin{array}{l}\text { Mixed } \\
\text { Response }\end{array}$ & Stable & Improved & $\begin{array}{l}\text { Total No. } \\
\text { of Patients } \\
(\mathrm{n}=29)\end{array}$ \\
\hline $\begin{array}{l}\text { Colorectal } \\
\text { Cancer }\end{array}$ & 8 & 1 & $1 *$ & 2 & 12 \\
\hline $\begin{array}{l}\text { Isle Cell } \\
\text { Tumors }\end{array}$ & 8 & - & $2 * *$ & - & 10 \\
\hline Carcinoid & 2 & - & $2 * * *$ & - & 4 \\
\hline NSCLC & 2 & - & - & 1 & 3 \\
\hline
\end{tabular}

NSCLC $=$ non-small cell lung cancer

*Stable for 10 months after Y-90 SIR-Spheres therapy

** One patient was stable for 13 months and the other patient for 9 months after Y-90 SIR-Spheres therapy.

*** One patient was stable for 3 months and the other patient for 1.3 month after Y-90 SIR-Spheres therapy.

Table 2: Response after Y-90 SIR-Spheres in patients with liver métastases from different tumor types. with very small representation from each type of tumor (Jiao et al., 2007). For example, they had only $2 / 21$ patient with neuroendocrine liver metastases and 1 with breast cancer liver metastasis. We demonstrated a $45 \%$ rate of responders to therapy while Gulec's group demonstrated $67 \%$ rate of responders. The difference between Gulec's results and ours is probably related to the larger degree of tumor burden in the liver in our patient population compared to theirs. As per our study, $45 \%$ of the patients had tumor burden greater than $50 \%$ of the liver in our study while in their population the mean tumor volume was approximately $17 \%$ of the mean liver volume. Meanwhile, the mean administered dose was $32.4 \mathrm{mCi}(1.2 \mathrm{GBq})$ in Gulec's study population versus $39.8 \mathrm{mCi}(1.5 \mathrm{GBq})$ in our population. Thus, the difference in the liver tumor burden was much larger in their study population and ours than the mean dose difference.

It is interesting that $4 / 13$ patients $(31 \%)$ with neuroendocrine tumors and $1 / 3$ patients with non-small cell lung cancer demonstrated either stability in their metastases or a decrease in the metastases size in this study. Although the numbers are still small, the results suggest that this method of therapy can be beneficial in approximately one third of patients with liver metastases from neuroendocrine tumors and possibly non-small cell lung cancer. Further studies with larger number of patients with these tumor types are needed.

The adverse effects of the treatment were only grade 1 or 2 in most of the patients (55\%) in our study. This supports the initial phase two trials which investigated the incidence and severity of adverse events with this form of therapy (Lau et al., 1994; Mancini et al., 2006; Yorke et al., 1992). Thus, it is a reasonably tolerated form of therapy in most patients with only 3 patients (10\%) developing grade 3 toxicity (Sharma et al., 2007; Herba et al., 1998; Szyszko et al., 2007; Lawrence et al., 1995; CADTH, 2007). This would encourage repeat treatments in patients who benefit from initial therapy.

One limitation of our study is lack of consistent evaluation of liver function tests or tumor biomarkers at constantly scheduled intervals in many of our patients. This is mainly due to the retrospective nature of this study with no consistency in biochemical investigation of these patients. However, our impression is that the changes of biomarkers and liver function tests are usually difficult to use to assess the response to the radioembolization therapy secondary to the advanced nature of tumor spread in these patients both in the liver and possibly in other sites. Another limitation is the lack of use of the RECEST criteria to evaluate the response to therapy on CT scans. However, we opted to use a method that is similar to what is usually used in the routine clinical setting during the interpretation of the CT scans on a daily basis in our institution. This method is usually what is used clinically for further patients' management decisions.

In conclusion, Y-90 SIR-Spheres is a useful therapeutic alternative for multiple liver metastases from a variety of tumors. The side effects are usually well tolerated with mostly grade 1 or 2 toxicity.

\section{References}

1. Canadian Agency for Drugs and Technologies in Health (2007) Yttrium-90 microspheres (Therashere and SIR-Spheres) for the treatment of unresectable hepatocellular Carcinoma. » CrossRef » PubMed » Google Scholar

J Cancer Sci Ther
Volume 2(2) : 043-046 (2010) - 045 
Citation: Gayed IW, Wahba H, Wan D, Joseph U, Murthy R (2010) Effect of Y-90 SIR-Spheres Therapy for Multiple Liver Metastases in a Variety of Tumors. J Cancer Sci Ther 2: 043-046. doi:10.4172/1948-5956.1000021

2. Gray BN, Anderson JE, Burton MA, van Hazel G, Codde J, et al. (1992) Regression of liver metastases following treatment with yttrium-90 microspheres. Aust N Z J Surg 62: 105-10. »CrossRef » PubMed » Google Scholar

3. Gray B, Van Hazel G, Hope M, Burton M, Moroz P, et al. (2001) Randomized trial of SIR-Spheres plus chemotherapy vs. chemotherapy alone for treating patients with liver metastases from primary large bowel cancer. Ann Oncol 12: 1711-20. » CrossRef » PubMed » Google Scholar

4. Gulec SA, Mesoloras G, Dezarn WA, McNeillie P, Kennedy AS (2007) Safety and efficacy of Y-90 microsphere treatment in patients with primary and metastatic liver cancer: The tumor selectivity of the treatment as a function of tumor to liver flow ratio. J Transl Med 5: 15. »CrossRef » PubMed » Google Scholar

5. Herba MJ, Illescas FF, Thirlwell MP, Boos GJ, Rosenthall L, et al. (1998) Hepatic malignancies: improved treatment with intraarterial Y-90. Radiology 169: 3114. »CrossRef » PubMed » Google Scholar

6. Ho S, Lau WY, Leung TW, Johnson PJ (1998) Internal radiation therapy for patients with primary or metastatic hepatic cancer: a review. Cancer 83: 1894907. » CrossRef » PubMed » Google Scholar

7. Jiao LR, Szyszko T, Al-Nahhas A, Tait P, Canelo R, et al. (2007) Clinical and imaging experience with yttrium-90 microspheres in the management of unrespectable liver tumors. Eur J Surg Oncol 33: 597-602. » CrossRef » PubMed » Google Scholar

8. Kennedy AS, Coldwell D, Nutting C, Murthy R, Wertman DE Jr, et al. (2006) Resin 90Y-microsphere brachytherapy for unresectable colorectal liver metastases: modern USA experience. Int J Radiat Oncol Biol Phys 65: 412-25. »CrossRef » PubMed » Google Scholar

9. Lau WY, Ho S, Leung TW, Chan M, Ho R, et al. (1998) Selective internal radiation therapy for nonresectable hepatocellular carcinoma with intraarterial infusion of 90 yttrium microspheres. Int J Radiat Oncol Biol Phys 40: 583-92. »CrossRef » PubMed » Google Scholar

10. Lau WY, Leung WT, Ho S, Leung NW, Chan M, et al. (1994) Treatment of inoperable hepatocellular carcinoma with intrahepatic arterial yttrium-90 microspheres: a phase I and II study. Br J Cancer 70: 994-9. »CrossRef » PubMed » Google Scholar

11. Lawrence TS, Robertson JM, Anscher MS, Jirtle RL, Ensminger WD, et al. (1995) Hepatic toxicity resulting from cancer treatment. Int J Radiat Oncol Biol Phys 31: 1237-48. » CrossRef » PubMed » Google Scholar
12. Lim L, Gibbs P, Yip D, Shapiro JD, Dowling R, et al. (2005) A prospective evaluation of treatment with Selective Internal Radiation Therapy (SIR-Spheres) in patients with unresectable liver metastases from colorectal cancer previously treated with 5-FU based chemotherapy. BMC Cancer 5: 132. »CrossRef » PubMed » Google Scholar

13. Mancini R, Carpanese L, Sciuto R, Pizzi G, Golfieri R, et al. (2006) Amulticentric phase II clinical trial on intra-arterial hepatic radiotherapy with $90 y$ ttrium SIRSpheres in unresectable, colorectal liver metastases refractory to i.v. chemotherapy: preliminary results on toxicity and response rates. In Vivo 2006; 20: 711-4. »CrossRef » PubMed » Google Scholar

14. Murthy R, Nunez R, Szklaruk J, Erwin W, Madoff DC, et al. (2005) Yttrium90 microsphere therapy for hepatic malignancy: devices, indications, technical considerations, and potential complications. Radiographics 1: S41-55. „CrossRef » PubMed » Google Scholar

15. National Cancer Institute (2006) Common Terminology criteria for adverse events v3.0. CTCAE 56-59. » CrossRef » PubMed » Google Scholar

16. Sangro B, Bilbao JI, Boan J, Martinez-Cuesta A, Benito A, et al. (2006) Radioembolization using 90Y-resin microspheres for patients with advanced hepatocellular carcinoma. Int J Radiat Oncol Biol Phys 66: 792-800. »CrossRef » PubMed » Google Scholar

17. Sharma RA, Van Hazel GA, Morgan B, Berry DP, Blanshard K, et al. (2007) Radioembolization of liver metastases from colorectal cancer using yttrium-90 microspheres with concomitant systemic oxaliplatin, fluorouracil, and leucovorin chemotherapy. J Clin Oncol 25: 1099-106. » CrossRef » PubMed » Google Scholar

18. Stubbs R, Wickremesekera S (2004) Selective internal radiation therapy (SIRT): a new modality for treating patients with colorectal liver metastases. HPB 6: 133-9. » CrossRef » PubMed » Google Scholar

19. Szyszko T, Al-Nahhas A, Tait P, Rubello D, Canelo R, et al. (2007) Management and prevention of adverse effects related to treatment of liver tumors with $90 \mathrm{Y}$ microspheres. Nucl Med Commun 28: 21-4. »CrossRef » PubMed » Google Scholar

20. Wong CY, Savin M, Sherpa KM, Qing F, Campbell J, et al. (2006) Regional yttrium-90 microsphere treatment of surgically unresectable and chemotherapyrefractory metastatic liver carcinoma. Cancer Biotherapy radiopharm 21: 305 13. »CrossRef » PubMed » Google Scholar

21. Yorke ED, Jackson A, Fox RA, Wessels BW, Gray BN (1999) Can current models explain the lack of liver complications in Y-90 microsphere therapy? Clin Cancer Res 5: 3024s-3030s. » CrossRef » PubMed » Google Scholar 